\section{Physical Activity, Physical Fitness and Coronary Heart Disease Risk Factors in Collegiate Women}

\author{
Hiroyuki Imamura, ${ }^{*},{ }^{a}$ Yoshitaka Yoshimura, ${ }^{b}$ \\ Kyota Okishima, ${ }^{c}$ Kazuhide Iide, ${ }^{d}$ \\ Reika Masuda, ${ }^{e}$ Yuka Noda, ${ }^{e}$ \\ Reina Kishida, ${ }^{e}$ and Atsumi Nagata ${ }^{e}$
}

${ }^{a}$ Faculty of Health Management, Department of Health and Nutrition, Nagasaki International University, 2825-7 Huis Ten Bosch, Sasebo-shi, Nagasaki 859-3298, Japan, ${ }^{b}$ Department of Food and Nutrition, Beppu University, 82 Kitaishigaki, Beppu-shi, Ohita 874-8501, Japan, ' School of Health Care Sciences, Himeji Dokkyo University, 7-2-1 Kamiohno, Himejishi, Hyogo 670-8524, Japan, ${ }^{d}$ Department of Physical Education, International Pacific University, 721 Kannonji setocho, Higashi-ku, Okayama 709-0863, Japan and ${ }^{e}$ Department of Nutritional Sciences, Nakamura Gakuen University, 5-7-1 Befu, Johnan-ku, Fukuoka 814-0198, Japan

(Received December 16, 2008; Accepted May 19, 2009; Published online June 3, 2009)

The purpose of this study was: to validate metabolic equivalents (METs) $\cdot \mathrm{hr} /$ week by comparing with maximal oxygen uptake $\left(\dot{\mathrm{V}} \mathrm{O}_{2} \mathrm{max}\right)$ as a measure of physical activities, to examine the relationships between METs $\cdot h r / w e e k, ~ \dot{V} O_{2}$ max, and coronary heart disease (CHD) risk factors according to the goals of METs $\cdot h r / w e e k$ and $\dot{\mathrm{V}} \mathrm{O}_{2}$ max in $\mathrm{ml} \cdot \mathrm{kg}^{-1} \cdot \mathrm{min}^{-1}$ for health promotion set in the Exercise Guide 2006, and to examine which is more related with CHD risk factors: METs $\cdot \mathrm{hr} /$ week or $\dot{\mathrm{V}} \mathrm{O}_{2} \max$ in $\mathrm{ml} \cdot \mathrm{kg}^{-1} \cdot \mathrm{min}^{-1}$ ? Subjects were $116 \mathrm{col}-$ legiate women. MET intensities were assigned to each specific activity. $\dot{\mathrm{V}} \mathrm{O}_{2}$ max was estimated with a bicycle ergometer. METs $\cdot \mathrm{hr} /$ week was significantly correlated $(r=0.514, p<0.01)$ with $\dot{\mathrm{V}} \mathrm{O}_{2}$ max in $\mathrm{ml} \cdot \mathrm{kg}^{-1} \cdot \mathrm{min}^{-1}$. After adjusting appropriate confounding factors in the forward stepwise multiple regression analyses, METs $\cdot h r / w e e k$ was significantly positively related with high-density lipoprotein cholesterol (HDL-C), while the estimated $\dot{\mathrm{V}} \mathrm{O}_{2}$ max in $\mathbf{m l} \cdot \mathrm{kg}^{-1} \cdot \mathrm{min}^{-1}$ was significantly positively related with HDL-C and total cholesterol (TC) and negatively

*To whom correspondence should be addressed: Faculty of Health Management, Department of Health and Nutrition, Nagasaki International University, 2825-7 Huis Ten Bosch, Sasebo-shi, Nagasaki 859-3298, Japan. Tel. \& Fax: +81-95620-5838; E-mail: himamura@niu.ac.jp related with log systolic blood pressure (SBP). After adjusting for body mass index (BMI) in the analysis of covariance, the highest category of METs $\cdot \mathrm{hr} /$ week ( $\geqq 23$ ) had significantly higher HDL-C than other lower categories. The highest category of $\dot{\mathrm{V}} \mathrm{O}_{2} \mathrm{max}$ $\left(\geqq 33 \mathrm{ml} \cdot \mathrm{kg}^{-1} \cdot \mathrm{min}^{-1}\right.$ ) had significantly higher HDL$\mathrm{C}$ and TC and lower SBP than the lowest category. In conclusion, METs $\cdot h r / w e e k$ was valid measures for quantifying physical activity, and the goals of METs $\cdot \mathrm{hr} /$ week and $\dot{\mathrm{V}} \mathrm{O}_{2} \mathrm{max}$ in $\mathrm{ml} \cdot \mathrm{kg}^{-1} \cdot \mathrm{min}^{-1}$ set in the Exercise Guide 2006 were valid. $\dot{\mathrm{V}} \mathrm{O}_{2}$ max in $\mathrm{ml} \cdot \mathrm{kg}^{-1} \cdot \mathrm{min}^{-1}$ was related to greater number of $\mathrm{CHD}$ risk factors than METs $\cdot h r / w e e k$ in young women.

Key words — metabolic equivalent·hour/week, maximal oxygen uptake, intensity, quantity of physical activity

\section{INTRODUCTION}

Valid assessment of physical activity in epidemiological studies is critical to evaluate not only its health effects but also as a confounding factor. The "Compendium of Physical Activities" (Compendium) has been developed by Ainsworth et al., ${ }^{1,2)}$ in which all physical activities were assigned an intensity unit based on their rate of energy expenditure expressed as metabolic equivalent (MET). Internationally, the Compendium has been used to identify MET intensities for physical activities, ${ }^{2)}$ from which the quantity of physical activity was expressed in a unit, METs · hr/week, calculated by multiplying the intensity of physical activity in METs by the duration of the activity in hour.

In 2006, the Ministry of Health, Labour and Welfare of Japan published the "Exercise and Physical Activity Reference for Health Promotion 2006: Physical Activity, Exercise, and Physical Fitness" (Exercise Guide 2006). In the Exercise Guide 2006, the goal of quantity of physical activity for health promotion was set at 23 METs $\cdot$ hr/week, of which 4 METs $\cdot$ hr/week or more by active exercise. ${ }^{3)}$ Also, the goal of physical fitness in terms of maximal oxygen uptake $\left(\mathrm{VO}_{2} \max \right)$ was set at $33 \mathrm{ml} \cdot \mathrm{kg}^{-1} \cdot \mathrm{min}^{-1}$ for young women, ranging from 20 to 29 years of age.

Although the MET values of physical activities listed in the Compendium were collected primarily from the physical activity energy expenditure lists published in the U.S.A., and the Compendium was 
used to identify MET intensities for specific physical activities in the Exercise guide 2006 and in some studies in Japan, ${ }^{4-6)}$ as far as authors know, the METs $\cdot h r / w e e k$ calculated from the Compendium has not been validated in Japanese.

Although levels of physical activity and cardiorespiratory fitness have been reported to be related with coronary heart disease (CHD) risk factors, many cross sectional studies linked levels of either physical activity ${ }^{7,8)}$ or cardiorespiratory fitness $^{9-11)}$ with CHD risk factors. Less studies simultaneously investigated the relationships between levels of physical activity as well as cardiorespiratory fitness with CHD risk factors in children $^{12,13)}$ or middle-aged individuals, ${ }^{14-16)}$ which were reported from European and North American countries. To our knowledge there have been no studies simultaneously investigated the relationships between levels of physical activity as well as cardiorespiratory fitness with CHD risk factors in Japanese.

The purpose of this study was: to validate METs $\cdot h r / w e e k$ calculated from the Compendium by comparing with estimated $\dot{\mathrm{V}}_{2}$ max as a measure of physical activities, to examine the relationships between METs $\cdot \mathrm{hr}$ /week, $\mathrm{V}_{2}$ max, and CHD risk factors according to the goal of quantity of physical activity and estimated $\mathrm{VO}_{2}$ max for health promotion set in the Exercise Guide 2006, and to examine which is more related with CHD risk factors: METs $\cdot \mathrm{hr} /$ week or $\dot{\mathrm{V}}_{2} \max$ ?

\section{MATERIALS AND METHODS}

\section{Subjects and Self-administered Question-} naire _- One hundred sixteen collegiate women ranging from 18 to 22 years of age volunteered for this study. They were all non-smokers, drank alcohol less than once a week, and were not on any medication at the time of their participation in the study. Few days before blood sampling, information on physical activity was obtained via a self-administered questionnaire. Subjects marked the appropriate answers to the following questions.

Do you currently exercise? No (sedentary)/Yes (play various sports and/or walk or bicycle to commute). Subjects who marked Yes were asked to indicate the frequency, duration and mode of physical activity, including leisure time physical activities, sport club activities, and/or walking or bicycling to commute, from which MET intensities were
Table 1. MET Intensities for Specific Physical Activity

\begin{tabular}{llc}
\hline \hline Physical Activity & Mets & $n$ \\
\hline aerobics & 6 & 3 \\
weight lifting & 3 & 2 \\
golf & 3 & 1 \\
soccer & 7 & 11 \\
walking & 3 & 13 \\
cycling & 4 & 13 \\
jogging & 6 & 8 \\
swimming & 4 & 6 \\
stretching & 4 & 4 \\
table tennis & 4 & 4 \\
tennis & 6 & 5 \\
basketball & 8 & 2 \\
badminton & 4.5 & 6 \\
volleyball & 4 & 2 \\
home exercise & 4.5 & 2 \\
running & 6 & 2 \\
\hline
\end{tabular}

assigned to each specific activity. Fifty seven subjects answered Yes. Of these subjects, 25 subjects played sports or involved in certain physical activity one to 2 times per week, and the other 32 subjects more than 2.5 times per week. The reported physical activities, assigned METs, and number of subjects are shown in Table 1. Because none of the subjects was athlete, the value for leisure activity was taken over that for competitive sport from the Compendium ${ }^{1,2)}$ in which some subjects were performing multiple physical activities. The study protocol was approved by the Ethics Committee of the Nakamura Gakuen University and informed consent was obtained from each subject.

Measurements — The body weight and height were measured with the subjects in underwear to the nearest $0.1 \mathrm{~kg}$ and $0.1 \mathrm{~cm}$, respectively. The body mass index (BMI) was expressed as weight $/$ height $^{2}$ $\left(\mathrm{kg} / \mathrm{m}^{2}\right)$.

Physical exercise was not allowed $48 \mathrm{hr}$, and beverages other than water were not allowed $24 \mathrm{hr}$ prior to the blood sampling. Subjects arrived at the laboratory by $8: 00 \mathrm{hr}$. The temperature of the laboratory was set at $25^{\circ} \mathrm{C}$. The systolic blood pressure (SBP) and fifth phase diastolic BP (DBP) were measured by a trained nurse using a cuff and mercury sphygmomanometer after the subject had been sitting for more than $20 \mathrm{~min}$. After BP was measured, blood was drawn from the antecubital vein. Samples were analyzed by a local commercial laboratory (Fukuoka Medical Laboratory Inc., Fukuoka, Japan). All measurements were duplicated, and the results were reported within 7 days. Serum total 
cholesterol (TC) and triglycerides (TG) were analyzed by enzymatic methods. High-density lipoprotein cholesterol (HDL-C) was analyzed by direct assay with selective inhibition method. The reported coefficients of variation for intra-assay and inter-assay were less than $1 \%$ and $3 \%$ for TC, $5 \%$ and $7 \%$ for TG, $1 \%$ and $2 \%$ for HDL-C. Low density lipoprotein cholesterol (LDL-C) was calculated from the Friedewald formula. ${ }^{17)}$

Estimation of $\dot{\mathbf{V}} \mathbf{O}_{2} \mathbf{m a x}$ - Within few days after blood sample was taken, $\dot{\mathrm{V}}_{2}$ max was estimated with the ML-1400 system (Fukuda Denshi, INC., Tokyo, Japan) which incorporates a bicycle ergometer (Combi, Tokyo, Japan) and an electrocardiogram (Fukuda Denshi, INC.) in air-conditioned facility with a temperature set at $25^{\circ} \mathrm{C}$. With the subjects in a sitting position, the work load was preset at 40, 50, 60, and 70\% age-predicted $\mathrm{V}_{2} \max$ for stages 1 to 4 , respectively. The duration of each stage was set at $4 \mathrm{~min}$. A regression equation was derived from the heart rate (HR) and work rate values at 3-min-and-50-sec of loading in the second, third and fourth stages. By substituting HR value corresponding to an age-predicted $80 \%$ $\dot{\mathrm{V}}_{2}$ max, the work rate was calculated. From these values of $\mathrm{HR}$ and work rate, an estimate of $\mathrm{V}_{2}$ max was obtained using the nomogram of $\AA$ strand and Ryhming. ${ }^{18)}$ In a previous study, ${ }^{19)}$ we have validated the method used to estimate $\dot{\mathrm{VO}}_{2}$ max in the present study in 30 collegiate women. The estimated $\dot{\mathrm{V}} \mathrm{O}_{2} \mathrm{max}$ in $\mathrm{ml} \cdot \mathrm{kg}^{-1} \cdot \mathrm{min}^{-1}$ significantly correlated with $\dot{\mathrm{V}}_{2}$ max measured with the standard open-circuit calorimetry $(r=0.656, p<0.05)$.

Statistical Analysis — Statistical analyses were performed with SPSS for Windows (Version 10.0J; SPSS Inc., Chicago, IL, U.S.A.). Descriptive statistics included the mean \pm S.D. and median. One sample Kolmogorov-Smirnov test was performed to examine whether or not each parameter was normally distributed. Logarithmic transformations of age (log age), TG (log TG), SBP (log SBP), and METs $\cdot$ hr/week (log METs $\cdot$ hr/week) were used to normalize a grossly skewed $(p<0.05)$ distribution of these parameters. Pearson correlation coefficients were used to examine simple correlations between 2 variables. Multiple regression analyses were performed, in which the number of independent variables $\left(\log\right.$ METs $\cdot \mathrm{hr} /$ week, $\mathrm{V}_{2}$ max in $\mathrm{ml} \cdot \mathrm{kg}^{-1} \cdot \mathrm{min}^{-1}, \log$ age, and BMI) included in each model was limited to variables which showed significant correlations $(p<0.05)$ with dependent variables (log SBP, DBP, TC, HDL-C, LDL-C,
TC/HDL-C, $\log$ TG). In the multiple regression analysis, only variables that significantly $(p<0.05)$ contributed to the $R^{2}$ were considered independent determinants of each dependent variable. Analysis of covariance was performed to adjust mean values for possible influences of confounding factors. A two-sided $p<0.05$ was considered to be statistically significant.

\section{RESULTS}

Log METs $\cdot h r / w e e k$ was significantly correlated $(r=0.514, p<0.01)$ with estimated $\dot{\mathrm{V}}_{2} \max$ in $\mathrm{ml} \cdot \mathrm{kg}^{-1} \cdot \mathrm{min}^{-1}$ (data not shown).

The characteristics of the subjects are shown in Table 2.

Pearson correlation coefficients are shown in Table 3. The $\log$ METs $\cdot \mathrm{hr} /$ week significantly positively correlated with HDL-C. The estimated $\dot{\mathrm{VO}}_{2} \mathrm{max}$ in $\mathrm{ml} \cdot \mathrm{kg}^{-1} \cdot \mathrm{min}^{-1}$, significantly positively correlated with HDL-C and TC, and negatively with $\log$ SBP. BMI significantly positively correlated with $\log$ SBP and TC/HDL-C. Because the log age did not correlate with any of the BP, lipids and lipoproteins, we adjusted only BMI in the following analyses presented from Table 4 to 6 .

Multiple regression analyses are shown in Table 4. Because log METs $\cdot \mathrm{hr} /$ week and estimated $\dot{\mathrm{V}} \mathrm{O}_{2} \mathrm{max}$ in $\mathrm{ml} \cdot \mathrm{kg}^{-1} \cdot \mathrm{min}^{-1}$ were significantly cor-

Table 2. Subject Characteristics $(n=116)$

\begin{tabular}{lrrrr}
\hline \hline & \multicolumn{2}{c}{ Mean \pm S.D. } & Median \\
\hline Age $(\mathrm{yr})$ & 19.9 & \pm & 0.8 & 20.0 \\
Height $(\mathrm{cm})$ & 158.4 & \pm & 4.6 & 158.2 \\
Weiht $(\mathrm{kg})$ & 52.8 & \pm & 6.6 & 51.9 \\
$\mathrm{BMI}\left(\mathrm{kg} / \mathrm{m}^{2}\right)$ & 21.0 & \pm & 2.2 & 20.9 \\
Waist $(\mathrm{cm})$ & 63.7 & \pm & 4.9 & 63.5 \\
$\dot{\mathrm{V}}{ }_{2} \mathrm{max}(\mathrm{ml})$ & 1675.0 & \pm 281.0 & 1643.4 \\
$\dot{\mathrm{VO}}{ }_{2} \mathrm{max}\left(\mathrm{ml} \cdot \mathrm{kg}^{-1} \cdot \mathrm{min}^{-1}\right)$ & 31.9 & \pm & 4.8 & 31.4 \\
$\mathrm{METs} \cdot \mathrm{hr} / \mathrm{week}$ & $18.8 \pm$ & 29.7 & 9.6 \\
$\mathrm{SBP}(\mathrm{mmHg})$ & 106 & \pm & 10 & 104 \\
$\mathrm{DBP}(\mathrm{mmHg})$ & 58 & \pm & 7 & 58 \\
$\mathrm{TC}(\mathrm{mol} / \mathrm{l})$ & $4.14 \pm$ & 0.74 & 4.03 \\
$\mathrm{HDL}-\mathrm{C}(\mathrm{mol} / \mathrm{l})$ & $1.54 \pm$ & 0.26 & 1.54 \\
$\mathrm{TC} / \mathrm{HDL}-\mathrm{C}(\mathrm{mol} / \mathrm{l})$ & $2.70 \pm$ & 0.70 & 2.64 \\
$\mathrm{LDL}-\mathrm{C}(\mathrm{mol} / \mathrm{l})$ & $2.25 \pm$ & 0.63 & 2.13 \\
$\mathrm{TG}(\mathrm{mol} / \mathrm{l})$ & $0.78 \pm$ & 0.34 & 0.72 \\
\hline $\log \mathrm{Age}$ & $1.30 \pm$ & 0.02 & 1.30 \\
$\log \mathrm{SBP}$ & $2.02 \pm$ & 0.04 & 2.02 \\
$\log \mathrm{TG}$ & $1.80 \pm$ & 0.17 & 1.81 \\
$\log \mathrm{Mets}$ & $1.07 \pm$ & 0.46 & 1.05 \\
\hline
\end{tabular}


Table 3. Pearson Correlation Coefficients $(n=116)$

\begin{tabular}{|c|c|c|c|c|c|c|c|}
\hline & $\log \mathrm{SBP}$ & $\overline{\mathrm{DBP}}$ & TC & HDL-C & LDL-C & TC/HDL-C & $\log \mathrm{TG}$ \\
\hline $\begin{array}{l}\text { log METs. } \\
\text { hr/week }\end{array}$ & -0.007 & 0.000 & 0.094 & $0.286^{* *}$ & 0.017 & -0.150 & -0.154 \\
\hline $\begin{array}{l}\dot{\mathrm{VO}_{2}} \max \\
\left(\mathrm{ml} \cdot \mathrm{kg}^{-1} \cdot \mathrm{min}^{-1}\right)\end{array}$ & $-0.247^{* *}$ & -0.121 & $0.198^{*}$ & $0.267^{* *}$ & 0.118 & -0.057 & -0.064 \\
\hline log Age & -0.033 & 0.076 & 0.072 & -0.066 & 0.136 & 0.105 & -0.113 \\
\hline BMI $\left(\mathrm{kg} / \mathrm{m}^{2}\right)$ & $0.280^{* *}$ & 0.178 & 0.103 & -0.112 & 0.159 & $0.222^{*}$ & 0.035 \\
\hline
\end{tabular}

Table 4. Standardized Partial Regression Coefficients $(n=116)$

\begin{tabular}{|c|c|c|c|c|c|c|c|}
\hline & $\log$ SBP & DBP & $\mathrm{TC}$ & HDL-C & LDL-C & TC/HDL-C & $\log \mathrm{TG}$ \\
\hline $\begin{array}{l}\text { log METs . } \\
\text { hr/week }\end{array}$ & -0.009 & -0.001 & 0.094 & $0.287^{* *}$ & 0.016 & -0.151 & -0.154 \\
\hline BMI & $0.300^{* *}$ & $0.201^{*}$ & 0.057 & -0.147 & 0.112 & $0.208^{*}$ & 0.061 \\
\hline \multirow[t]{2}{*}{$R^{2}$} & 0.09 & 0.041 & 0.012 & 0.103 & 0.013 & 0.065 & 0.027 \\
\hline & $\log$ SBP & DBP & $\mathrm{TC}$ & HDL-C & LDL_C & TC/HDL-C & $\log \mathrm{TG}$ \\
\hline $\begin{array}{l}\dot{\mathrm{V} O_{2} \max } \\
\left(\mathrm{ml} \cdot \mathrm{kg} \cdot \mathrm{min}^{-1}\right)\end{array}$ & $-0.184^{*}$ & -0.079 & $0.245^{*}$ & $0.256^{* *}$ & 0.175 & 0.003 & -0.059 \\
\hline BMI & $0.230^{*}$ & 0.156 & 0.170 & -0.042 & $0.207^{*}$ & $0.223^{*}$ & 0.019 \\
\hline$R^{2}$ & 0.110 & 0.037 & 0.066 & 0.073 & 0.054 & 0.049 & 0.004 \\
\hline
\end{tabular}

TC/HDL-C, and log TG as dependent variables and $\log$ METs $\cdot \mathrm{hr} /$ week and BMI as independent variables. Model II: $\log$ SBP, DBP, TC, HDL-C, LDL-C, TC/HDL-C, and log TG as dependent variables and $\dot{\mathrm{VO}}_{2} \mathrm{max}$ in $\mathrm{ml} \cdot \mathrm{kg}^{-1} \cdot \mathrm{min}^{-1}$ and BMI as independent variables.

Table 5. Adjusted Mean ( \pm SE) Values According to METs $\cdot$ hr/week

\begin{tabular}{lcccc}
\hline \hline & \multicolumn{5}{c}{ Mets · hr/week } \\
\cline { 2 - 5 } & $(\leqq 3.3)$ & $(4.2-10.5)$ & $(10.8-22.3)$ & $(\geqq 23)$ \\
& $(n=30)$ & $(n=34)$ & $(n=33)$ & $(n=19)$ \\
\hline $\log \mathrm{SBP}$ & $2.02 \pm 0.01$ & $2.03 \pm 0.01$ & $2.02 \pm 0.01$ & $2.02 \pm 0.01$ \\
$\mathrm{SBP}(\mathrm{mmHg})$ & $106.3 \pm 1.8$ & $106.4 \pm 1.7$ & $104.1 \pm 1.7$ & $105.6 \pm 2.3$ \\
$\mathrm{DBP}(\mathrm{mmHg})$ & $57.8 \pm 1.34$ & $57.8 \pm 1.18$ & $57.1 \pm 1.24$ & $58.8 \pm 1.63$ \\
$\mathrm{TC}(\mathrm{mmol} / \mathrm{l})$ & $4.06 \pm 0.14$ & $4.12 \pm 0.12$ & $4.11 \pm 0.13$ & $4.37 \pm 0.17$ \\
$\mathrm{HDL}-\mathrm{C}(\mathrm{mmol} / \mathrm{l})$ & $1.51 \pm 0.05$ & $1.50 \pm 0.04$ & $1.51 \pm 0.04$ & $1.72 \pm 0.06^{*, \#, \dagger}$ \\
LDL-C $(\mathrm{mmol} / \mathrm{l})$ & $2.19 \pm 0.12$ & $2.23 \pm 0.11$ & $2.27 \pm 0.11$ & $2.32 \pm 0.15$ \\
TC/HDL-C & $2.7 \pm 0.1$ & $2.8 \pm 0.1$ & $2.8 \pm 0.1$ & $2.6 \pm 0.1$ \\
\hline \multicolumn{2}{c}{ Analysis of covariance was performed to adjust mean values for possible influence of BMI. ${ }^{*} p<0.05$, when com- }
\end{tabular}

Analysis of covariance was performed to adjust mean values for possible influence of BMI. ${ }^{*} p<0.05$, when compared with the lowest category. ${ }^{\#} p<0.05$, when compared with the second category. ${ }^{\dagger} p<0.05$, when compared with the third category.

related, these variables were added to the multiple regression analyses separately to avoid collinearity. Thus, we performed 2 sets of multiple regression analyses. In the Model I, log SBP, DBP, TC, HDLC, LDL-C, TC/HDL-C, and log TG were added as dependent variables and log METs $\cdot \mathrm{hr} /$ week and BMI as independent variables. In the Model II, $\log$ SBP, DBP, TC, HDL-C, LDL-C, TC/HDL-C, and $\log$ TG were added as dependent variables and $\dot{\mathrm{V}} \mathrm{O}_{2} \mathrm{max}$ in $\mathrm{ml} \cdot \mathrm{kg}^{-1} \cdot \mathrm{min}^{-1}$ and BMI as independent variables. The METs $\cdot \mathrm{hr} /$ week was significantly positively related with HDL-C. The estimated $\dot{\mathrm{VO}}_{2}$ max in $\mathrm{ml} \cdot \mathrm{kg}^{-1} \cdot \mathrm{min}^{-1}$ was significantly positively related with HDL-C and TC.

Table 5 presents the mean BP and lipids and lipoproteins according to the METs $\cdot \mathrm{hr} /$ week after 
Table 6. Adjusted Mean ( \pm SEM) Values According to $\dot{\mathrm{VO}}_{2} \max$

\begin{tabular}{|c|c|c|c|c|}
\hline & \multicolumn{4}{|c|}{ 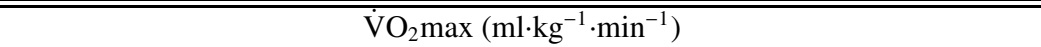 } \\
\hline & $(19.7-28.6)$ & $(28.7-30.8)$ & $(30.9-32.9)$ & $(33.0-45.1)$ \\
\hline & $(n=25)$ & $(n=26)$ & $(n=25)$ & $(n=40)$ \\
\hline $\log$ SBP & $2.04 \pm 0.01$ & $2.01 \pm 0.01^{*}$ & $2.02 \pm 0.01$ & $2.02 \pm 0.01^{*}$ \\
\hline $\mathrm{SBP}(\mathrm{mmHg})$ & $111 \pm 2$ & $103 \pm 2^{*}$ & $105 \pm 2$ & $104 \pm 2^{*}$ \\
\hline DBP $(\mathrm{mmHg})$ & $58.4 \pm 1.5$ & $57.6 \pm 1.4$ & $57.4 \pm 1.4$ & $57.8 \pm 1.1$ \\
\hline $\mathrm{TC}(\mathrm{mmol} / \mathrm{l})$ & $3.86 \pm 0.15$ & $4.18 \pm 0.14$ & $4.06 \pm 0.15$ & $4.34 \pm 0.12^{*}$ \\
\hline $\mathrm{HDL}-\mathrm{C}(\mathrm{mmol} / \mathrm{l})$ & $1.42 \pm 0.06$ & $1.57 \pm 0.05$ & $1.54 \pm 0.05$ & $1.59 \pm 0.04^{*}$ \\
\hline LDL-C (mmol/l) & $2.11 \pm 0.13$ & $2.26 \pm 0.12$ & $2.16 \pm 0.13$ & $2.38 \pm 0.10$ \\
\hline TC/HDL-C & $2.8 \pm 0.1$ & $2.7 \pm 0.1$ & $2.7 \pm 0.1$ & $2.8 \pm 0.9$ \\
\hline
\end{tabular}

Analysis of covariance was performed to adjust mean values for possible influence of BMI. ${ }^{*} p<0.05$, when compared with the lowest category.

adjusting for BMI. The subjects were divided into 4 groups: the highest category included 19 subjects whose METs.hr/week were above 23, and approximately equal number of subjects were included in the lower 3 categories. The highest category had significantly higher HDL-C (13.9-14.7\%) than other lower categories.

Table 6 presents the mean $\mathrm{BP}$ and lipids and lipoproteins according to the estimated $\mathrm{V}_{2}$ max in $\mathrm{ml} \cdot \mathrm{kg}^{-1} \cdot \mathrm{min}^{-1}$ after adjusting for BMI. The subjects were divided into 4 groups: the highest category included 40 subjects whose $\dot{\mathrm{V}}_{2}$ max were above $33 \mathrm{ml} \cdot \mathrm{kg}^{-1} \cdot \mathrm{min}^{-1}$, and approximately equal number of subjects were included in the lower 3 categories. The highest category had significantly higher HDL$\mathrm{C}$ and TC and lower SBP than the lowest category.

\section{DISCUSSION}

Several limitations of our study need to be mentioned. First, in the Exercise Guide 2006, the goals of quantity of physical activity and physical fitness were set for young women aged 20 to 29 years. However, younger women aged 18 and 19 years were included in the present study. Thus, the results obtained in the present study might differ from the results obtained in older women aged 25 to 29 years. Second, the cross-sectional nature of the study does not permit the assessment of causality owing to the uncertain temporality of the association.

In the studies simultaneously investigated the relationships between levels of physical activity as well as cardiorespiratory fitness with CHD risk factors, various methods were used to estimate physical fitness and physical activity levels. Young and Steinhardt, ${ }^{14)}$ using men aged $35.9 \pm 6.6$ years, re- ported a significant correlation $(r=0.57)$ between maximal time on the treadmill and activity scores $1-$ 5. Bouziotas et al., ${ }^{12)}$ using boys and girls aged 12 years, reported the similar result $(r=0.58)$ between $\dot{\mathrm{VO}}_{2}$ max predicted from the $20 \mathrm{~m}$ shuttle run test and total physical activity score expressed in kcal per kg per day. Løchen and Rasmussen, ${ }^{15)}$ using men and women aged 20 to 61 years, reported age adjusted correlations in men $(r=0.18)$ and women $(r=0.39)$ obtained between maximum work load (watts) performed on a bicycle exercise test and activity $1-4$. Suter and Hawes, ${ }^{13)}$ using boys and girls aged 10 to 15 years, reported significant correlations in boys $(r=0.40)$ and girls $(r=0.23)$ between a submaximal bicycle ergometer test and 7-d recall that contained a list of 23 popular activities. Eaton et al., ${ }^{16)}$ using middle-aged men and women, reported poor but significant correlations in both men $(r=0.13)$ and women $(r=0.19)$ between $\dot{\mathrm{VO}}_{2} \max$ estimated by a step test and doing vigorous exercise for $20 \mathrm{~min}$ or more once a week, 1 or 2 times a week, 3 or more times a week, or not at all. In the present study, we used the Compendium to identify MET intensities for physical activity and calculated the quantity of physical activity in METs $\cdot$ hr/week which reasonably correlated $(r=0.52, p<0.01)$ with estimated $\dot{\mathrm{V}} \mathrm{O}_{2} \max$ in $\mathrm{ml} \cdot \mathrm{kg}^{-1} \cdot \mathrm{min}^{-1}$. Thus, we consider that METs $\cdot \mathrm{hr} /$ week was valid measures for quantifying physical activity in epidemiological research.

In the Exercise Guide 2006, ${ }^{3)}$ the goals of quantity of physical activity and physical fitness for health promotion were set at $23 \mathrm{METs} \cdot \mathrm{hr} / \mathrm{week}$ and $33 \mathrm{ml} \cdot \mathrm{kg}^{-1} \cdot \mathrm{min}^{-1}$, respectively, for young women, ranging from 20 to 29 years of age. In the present study, when the subjects were divided into 4 groups according to METs $\cdot h r / w e e k$, the highest 
category ( $\geqq 23$ METs $\cdot h r / w e e k)$ had significantly higher HDL-C than other lower categories. Also, when the subjects were divided into 4 groups according to $\dot{\mathrm{V}} \mathrm{O}_{2} \mathrm{max}$ in $\mathrm{ml} \cdot \mathrm{kg}^{-1} \cdot \mathrm{min}^{-1}$, the highest category ( $\geqq 33 \mathrm{ml} \cdot \mathrm{kg}^{-1} \cdot \mathrm{min}^{-1}$ ) had significantly higher HDL-C and TC. However, the gradient trend was incoherence in SBP because the highest and second categories had lower SBP than the lowest category, but the third category did not show such trend. This could be due, at least in part, to the fact that although $\dot{\mathrm{VO}}_{2}$ max in $\mathrm{ml} \cdot \mathrm{kg}^{-1} \cdot \mathrm{min}^{-1}$ significantly correlated with METs $\cdot \mathrm{hr} /$ week, it also has a genetic component that can account for as much as $40 \%$ of the variability in fitness measures. ${ }^{20)}$ It might also be related to the cross-sectional nature of the present study. Although the results are somewhat variable, the results of the present study support the validity of the goals of quantity of physical activity and physical fitness for health promotion set in the Exercise Guide 2006.

According to the review article by Blair et al., ${ }^{21}$ ) physical activity and physical fitness are inversely associated with CHD morbidity in prospective studies. The cardioprotective mechanism appears in part to be related to the decreased BP, higher HDL-C, lower TC/HDL-C with physical activity and physical fitness. ${ }^{22-24)}$ The results of the present study support these studies although correlation coefficients and the differences were small. However, not only physical activity and physical fitness, but also other various confounding factors have been reported to influence CHD risk factors. For example, cigarette smoking has shown to be negatively associated with HDL-C, ${ }^{25)}$ while alcohol consumption appears to be positively associated with HDL-C. ${ }^{26)}$ Blood pressure tends to increase with age. ${ }^{27)}$ In the present study, the subjects were all non-smokers and drunken alcohol less than once a week. Also, log age did not significantly correlate with any of the $\mathrm{CDH}$ risk factors examined in the present study. Thus, influences of these confounding factors appear to be limited. Diet rich in saturated fatty acids can raise HDL-C but also increase LDL-C. ${ }^{28)}$ Individuals consuming a high-carbohydrate diet tend to show lower HDL-C than those who consume a lowcarbohydrate die. ${ }^{29)}$ However, no information on dietary intake was available in the present study. Because BMI was significantly associated with some of the CHD risk factors, we adjusted BMI in the multiple regression analyses and analysis of covariance.

Some studies in adult men and women reported that physical fitness was more related with CHD risk factors than physical activity. Leclerc et al. ${ }^{30)}$ using men aged 30 to 59 years, reported that HDL$\mathrm{C}$, TG, and TC/HDL-C were significantly associated with a progressive submaximal power output test (PWC150) on a cycle ergometer, but not with the mean daily energy expenditure computed from a 3-day activity record. However, when confounding factors were adjusted with multiple regression procedures, these relationships became nonsignificant, with the exception of TG and PWC150. Young and Steinhardt ${ }^{14)}$ reported that multivariate analysis of covariance revealed that physical fitness, but not physical activity, was positively associated with HDL-C after adjusting possible confounding factors. Løchen and Rasmussen ${ }^{15)}$ and Eaton et al. ${ }^{16)}$ also reported that physical fitness was found to have a stronger relationship with CHD risk factors than physical activity.

In conclusion, METs $\cdot \mathrm{hr} /$ week was valid measures for quantifying physical activity, and the goals of METs $\cdot \mathrm{hr} /$ week and $\mathrm{VO}_{2}$ max in $\mathrm{ml} \cdot \mathrm{kg}^{-1} \cdot \mathrm{min}^{-1}$ set in the Exercise Guide 2006 were valid. $\mathrm{V}_{2} \max$ in $\mathrm{ml} \cdot \mathrm{kg}^{-1} \cdot \mathrm{min}^{-1}$ was related to greater number of CHD risk factors than METs $\cdot \mathrm{hr} /$ week in young women.

Acknowledgements This study was supported by grants from the Nakamura Gakuen University and Nakamura Gakuen University Graduate School.

\section{REFERENCES}

1) Ainsworth, B. E., Haskell, W. L., Leon, A. S., Jacobs, D. R., Montoye, H. J., Sallis, J. F. and Paffenbarger, R. S. (1993) Compendium of physical activities: classification of energy cost of human physical activities. Med. Sci. Sports Exerc., 25, 7180.

2) Ainsworth, B. E., Haskell, W. L., Whitt, M. C., Irwin, W. L., Swartz, A. M., Strath, S. J., O'brien, W. L. and Bassett, D. R. (2000) Compendium of physical activities: an update of activity codes and MET intensities. Med. Sci. Sports Exerc., 32, S498S516.

3) Ministry of Health, Labour and Welfare of Japan (2006) Exercise and physical activity guide for health promotion 2006: to prevent lifestyle-related diseases.

4) Murakami, K., Sasaki, S., Okubo, H., Takahashi, Y., Hosoi, Y. and Itabashi, M. (2007) Association 
between dietary fiber, water and magnesium intake and functional constipation among young Japanese women. Eur. J. Clin. Nutr., 61, 616-622.

5) Murakami, K., Okubo, H. and Sasaki, S. (2006) Dietary intake in relation to self-reported constipation among Japanese women aged 18-20 years. Eur. J. Clin. Nutr., 60, 650-657.

6) Murakami, K., Sasaki, S., Takahashi, Y., Olubo, H., Hosoi, Y., Horiguchi, H. and Oguma, E. (2006) Dietary glycemic index and load in relation to metabolic risk factors in Japanese female farmers with traditional dietary habits. ${ }^{1-3}$ Am. J. Clin. Nutr., 83, 1161-1169.

7) Kruger, H. S., Venter, C. and Vorster, H. H. (2003) Physical inactivity as a risk factor for cardiovascular disease in communities undergoing rural to urban transition: the THUSA study. Cardiovasc. J. S. Afr., 14, 16-23.

8) Hsieh, S. D., Yoshinaga, H., Muto, T. and Sakurai, Y. (1998) Regular physical activity and coronary risk factors in Japanese men. Circulation, 97, 661-665.

9) LaMonte, M. J., Eisenman, P. A., Adams, T. D., Shultz, B. B., Ainsworth, B. E. and Yanowitz, F. G. (2000) Cardiorespiratory fitness and coronary heart disease risk factors. Circulation, 102, 1623-1628.

10) Jetté, M., Sidney, K. and Quenneville, J. (1992) Relation between cardiorespiratory fitness and selected risk factors for coronary heart disease in a population of Canadian men and women. Can. Med. Assoc. J., 146, 1353-1360.

11) Israel, R. G., Sullivan, M. J., Marks, R. H., Cayton, R. S. and Chenier, T. C. (1994) Relationship between cardiorespiratory fitness and lipoprotein (a) in men and women. Med. Sci. Sports Exerc., 26, 425-431.

12) Bouziotas, C., Koutedakis, Y., Nevill, A., Ageli, E., Tsigilis, N., Nikolaou, A. and Nakou, A. (2004) Greek adolescents, fitness, fatness, fat intake, activity, and coronary heart disease risk. Arch. Dis. Child., 89, 41-44.

13) Suter, E. and Hawes, M. R. (1993) Relationship of physical activity, body fat, diet, and blood lipid profile in youths 10-15 yr. Med. Sci. Sports Exerc., 25, 748-754.

14) Young, D. R. and Steinhardt, M. A. (1993) The importance of physical fitness versus physical activity for coronary artery disease risk factors: a crosssectional analysis. Res. Q. Exerc. Sport, 64, 377384.

15) Løchen, M.-L. and Rasmussen, K. (1992) The Troms $\varnothing$ study: physical fitness, self reported physical activity, and their relationship to other coronary risk factors. J. Epidemiol. Community Health, 26, 103-107.

16) Eaton, C. B., Lapane, K., Garber, C. E., Assaf, A. R., Lasater, T. M. and Carleton, R. A. (1995) Physical activity, physical fitness, and coronary heart disease risk factors. Med. Sci. Sports Exerc., 27, 340-346.

17) Friedewald, W. T., Levy, R. I. and Fredrickson, D. S. (1972) Estimation of the concentration of lowdensity lipoprotein cholesterol in plasma, without use of the preparative ultracentrifuge. Clin. Chem., 18, 499-502.

18) Åstrand, P. O. and Ryhming, I. (1954) A nomogram for calculation of aerobic capacity (physical fitness) from pulse rate during submaximal work. J. Appl. Physiol., 7, 218-221.

19) Yoshimura, Y., Imamura, H., Iide, K., Kyota, O. and Hamada, S. (2005) Validity of the values of estimated maximal oxygen uptake. Health Evalvation and Promotion, 32, 8-11 (in Japanese with English abstract).

20) Bouchard, C. (1990) Discussion: Heredity, fitness, and health, In Ecercise, fitness, and health: A consensus of current knowledge (Bouchard, C., Shepard, R. J., Stephens, T., Stephens, J. R., McPherson, B. D. Eds.), Champaign, IL, Human Kinetics, pp. 147-153.

21) Blair, S. N., Cheng, Y. and Holder, J. S. (2001) Is physical activity or physical fitness more important in defining health benefits? Med. Sci. Sports Exerc., 33, S379-S399.

22) Dannerberg, A. L., Keller, J. B., Wilson, P. W. and Castelli, W. P. (1989) Leisure-time physical activity in the Framingham Offspring Study. Description, seasonal variation, and risk factor correlates. Am. J. Epidemiol., 129, 76-78.

23) Eaton, C. B. (1992) Relation of physical activity and cardiovascular fitness to coronary heart disease. Part I: a meta-analysis of the independent relation of physical activity and coronary heart disease. J. Am. Board Fam. Pract., 5, 31-42.

24) Kannel, W. B., Wilson, P. and Blair, S. N. (1985) Epidemiological assessment of the role of physical activity and fitness in development cardiovascular disease. Am. Heart J., 109, 876-885.

25) Imamura, H., Teshima, K., Miyamoto, N. and Shirota, T. (2002) Cigarette smoking, high-density lipoprotein cholesterol subfractions, and lecithin: cholesterol acyltransferase in young women. Metabolism, 51, 1313-1316.

26) Gaziano, J. M., Buring, J. E., Breslow, J. L., Goldhaber, S. Z., Rosner, B., VanDenburgh, M., Willett, W. and Hennekens, C. H. (1993) Moderate alcohol intake, increased levels of high-density 
lipoprotein and its subfractions, and decreased risk of myocardial infarction. N. Engl. J. Med., 329, 1829-1834.

27) Green, M. S., Jucha, E. and Luz, Y. (1986) Blood pressure in smokers and nonsmokers: Epidemiologic findings. Am. Heart J., 111, 932-940.

28) Nicholls, S. J., Lundman, P. and Harmer, J. A. (2006) Consumption of saturated fat impairs the anti-inflammatory properties of high-density lipoproteins and endothelial function. J. Am. Coll. Cardiol., 48, 715-720.

29) Merchant, A. T., Anand, S. S. and Kelemen, L. E. (2007) Carbohydrate intake and HDL in a multiethnic population. Am. J. Clin. Nutr., 85, 225-230.

30) Leclerc, S., Allard, C., Talbot, J. Gauvin, R. and Bouchard, C. (1985) High density lipoprotein cholesterol, habitual physical activity and physical fitness. Atherosclerosis, 57, 43-51. 